Chapter 9

\title{
Application of Glass Beads in Building Exterior Wall Surface Materials
}

\author{
Jihui Yuan
}

Additional information is available at the end of the chapter

http://dx.doi.org/10.5772/intechopen.73292

\begin{abstract}
Glass beads are solid glass spheres. Because of their high strength, chemical stability, low thermal expansion, and good flowability, they are manufactured from colorless glass for many industrial purposes. In recent years, the urban heat island (UHI) phenomenon has become very serious in urban centers. Heat emitted from exterior walls of buildings accounts for a relatively large proportion of total anthropogenic waste heat. Retroreflective (RR) materials are researched worldwide for the potential in application to building exterior wall surface instead of normal diffuse highly reflective (DHR) materials to resist the UHI. Glass beads are the common main components of these RR materials. Glass beads have different refractive indices and diameters. The classification and reflection principles of glass beads, experimental analysis on the optical properties and thermal performance of glass bead RR materials are elaborated in detail in this chapter. In addition, if these glass bead RR materials are used in building facades, when the incident angle of the sun is very high, the facade will produce a large specular reflection to the road, which may cause adverse effects on pedestrians. Therefore, theoretical and technical aspects of preventing the specular reflection from glass bead RR materials should be studied and implemented.
\end{abstract}

Keywords: urban heat island, building façade materials, retroreflective materials, glass beads, experimental analysis

\section{Introduction}

Glass beads are solid glass spheres. Because of their high strength, chemical stability, limited thermal expansion, and good flowability, they are manufactured from colorless glass for several industry purposes and widely used for blasting, filler, and traffic safety. 


\subsection{Glass bead retroreflective materials}

In recent years, the urban heat island (UHI) phenomenon has become serious in urban centers. Among the factors of increasing UHI, the urbanization has been considered as one of the main reasons. Urban constructions are important parts of the urbanization. Heat emitted from exterior walls of buildings accounts for a relatively large proportion of total anthropogenic waste heat. Therefore, many countermeasures of mitigating UHI and saving energy of buildings have been implemented by means of high reflection of the building's exterior wall surface. There are usually three kinds of reflections: diffuse reflection, specular reflection, and retroreflection.

At present, in order to be possibly applied to building exterior wall surface to resist the UHI and save energy consumption of buildings, retroreflective (RR) materials are recommended and researched by scholars worldwide instead of the normal diffuse highly reflective (DHR) materials [1-3]. Glass beads are the common main components of these RR materials. The principle of retroreflection of glass bead is shown in Figure 1 [4].

Currently, several types of RR materials are commercially available in Japan (as shown in Figures 2-5 [5, 6]). However, they are employed for various safety and decorative purposes and are useful at nighttime when visibility is important under low-light conditions. As for application to building envelopes, RR materials have not been widely used yet [7]. In order to possibly apply these commercially available RR materials to building the exterior wall surface, their weatherability must be ensured. In the design of buildings, those building materials that are uneasy to maintain won't be considered to be used for the exterior wall surface, since safety is given the highest priority.

Hence, long-term durability of new building's exterior wall surface materials should be verified by a long-term exposure experiment. Afterward, they can be practically applied to exterior wall surface of buildings.

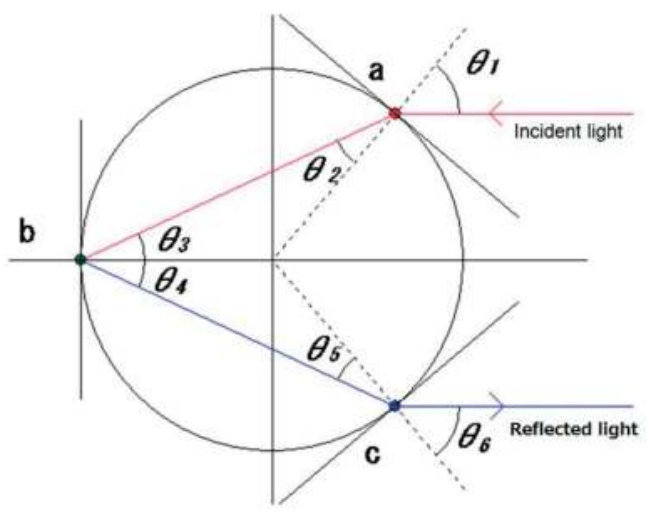

Figure 1. Principle of retroreflection of glass bead. 


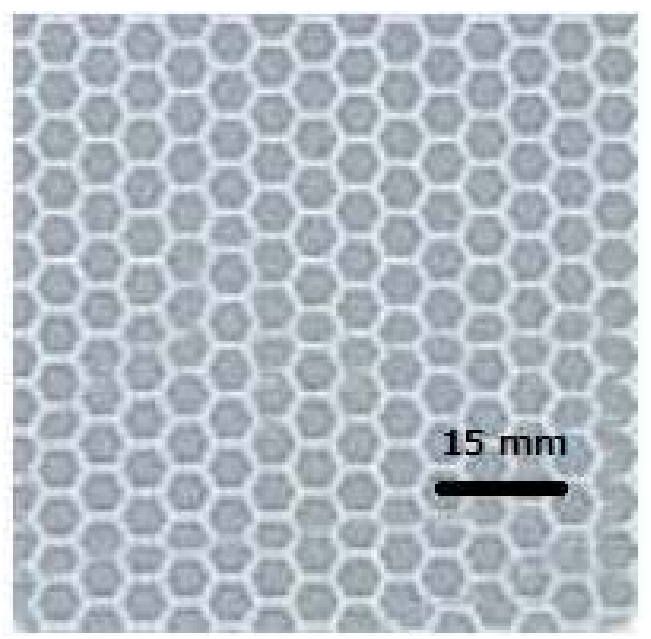

Figure 2. Appearance of lens-type RR material.

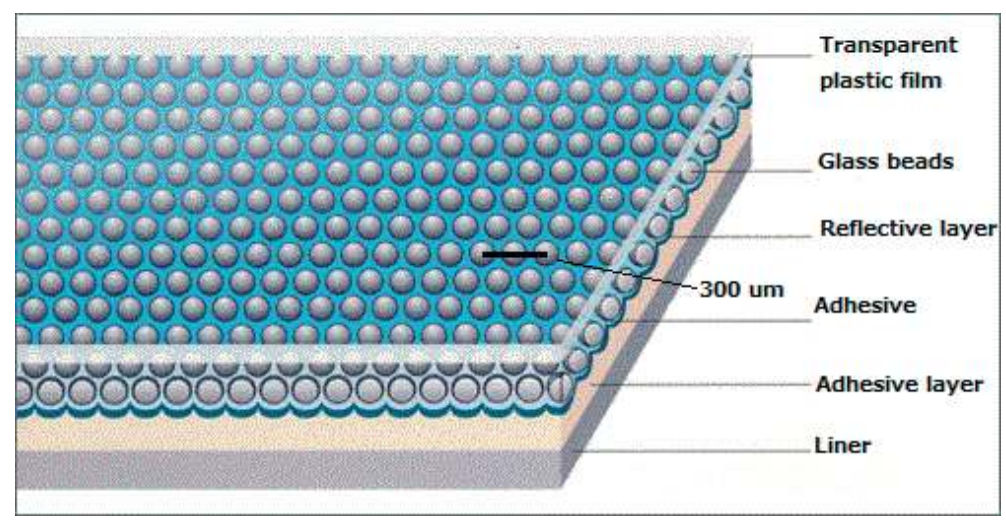

Figure 3. Sectional structure of lens-type RR material.

\subsection{Impact on building energy consumption and urban albedo}

The same as a DHR material, RR material applied to building facades can decrease the energy consumption of buildings during the cooling period, whereas it can increase the energy consumption of buildings during heating period. Previous research indicated that when comparing the annual thermal load of a simulated building (air-conditioned area $=605 \mathrm{~m}^{2}$ ) located in Shanghai, China, with RR facade to that with no RR facade, the yearly cooling load is reduced by about $157 \mathrm{MJ} /\left(\mathrm{m}^{2}\right.$-year) (19\%). However, the yearly heating load is increased by about $71 \mathrm{MJ} /\left(\mathrm{m}^{2}\right.$-year) $(6 \%)$. In general, the total load of the simulated building is decreased by about $86 \mathrm{MJ} /\left(\mathrm{m}^{2}\right.$-year) $(4.3 \%)$ when the RR façade is 


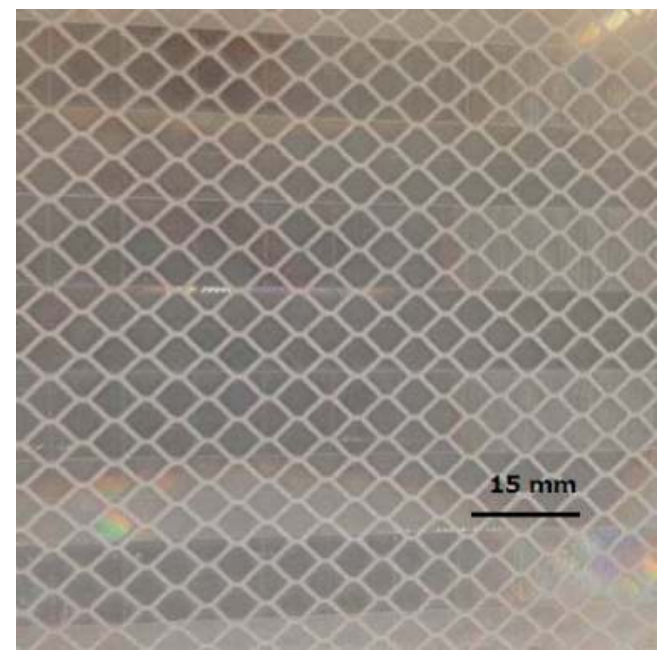

Figure 4. Appearance of prism-type RR material.

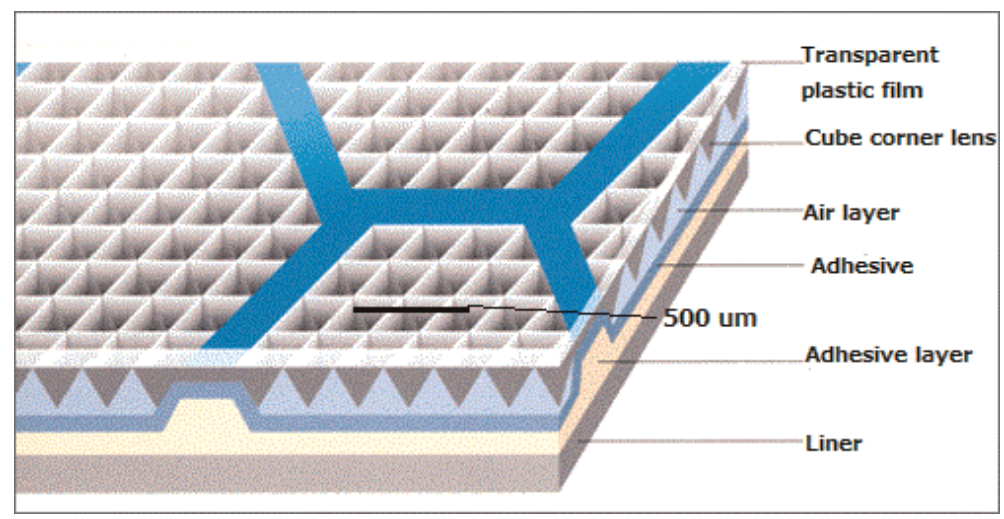

Figure 5. Sectional structure of prism-type RR material.

adopted [8]. A research related to the influence of RR materials on the energy consumption of public buildings in different climatic regions of China showed that the RR coating materials are more effective in the cooling-dominated area (i.e., Guangzhou) than the heating-dominated area (i.e., Harbin) [9]. A research, which is related to the thermal energy impact of RR and DHR envelopes on energy consumptions of buildings in different metropolitan areas of the United States, was analyzed via using the EnergyPlus software [3]. Results showed that the total energy consumption and cooling energy consumption of heating, ventilation and air conditioning (HVAC) are reduced by 8.2 and $9.8 \%$, respectively, under the RR context. 
Compared to building exterior wall surface materials with DHR and specular reflective characteristics, a previous research by a two-dimensional urban canyon space model showed that the RR coating of buildings is the most effective to increase the urban albedo [8]. A research showed that the RR materials could be effectively applied to urban pavements and building envelopes to improve the urban albedo [2].

\subsection{Motivation and purpose}

For possible application of glass bead RR materials to exterior wall surface of buildings, methods of thermal and optical characteristics analysis and durability testing of glass bead RR materials are summarized and elaborated in this study. In addition, if these glass bead RR materials are applied to building facades, when the angle of sunlight incident on the facade surface is high, the facade surface produces a large specular reflection on the road, which may cause adverse effects on pedestrians. Therefore, theoretical and technical aspects of preventing the specular reflection from glass bead RR materials should be studied and implemented. A theoretical possibility of preventing the specular reflection through appropriate design of glass bead RR materials will also be proposed in this study.

\section{Methods to derive retroreflectivity of RR materials}

There are two main methods to obtain retroreflectivity of RR materials: one is measured by a spectrophotometer system [10] (as shown in Figure 6) and the other is determined by a thermal balance principle of surface [11] (as shown in Figure 7).

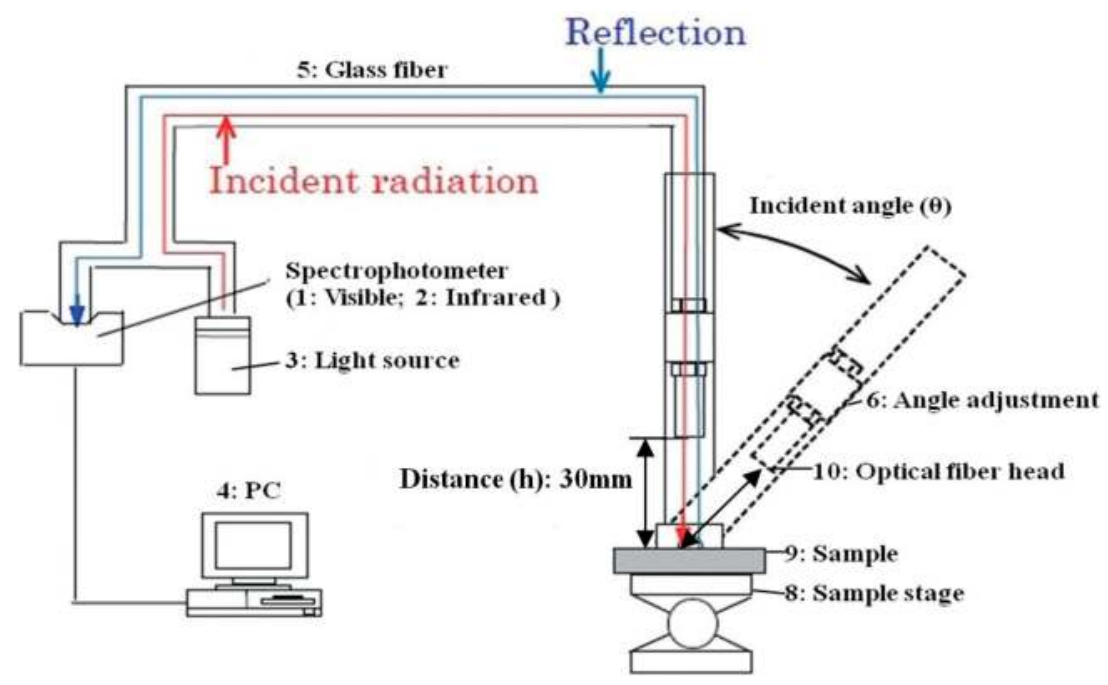

Figure 6. A diagrammatic general view of the spectrophotometer system. 


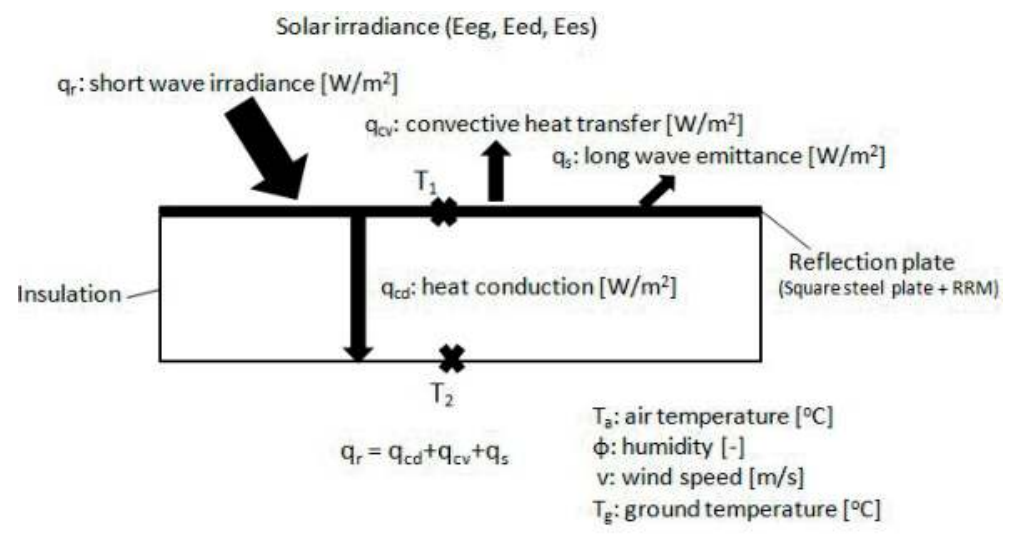

Figure 7. A conceptual diagram of the thermal balance of RR materials.

\subsection{Determination of retroreflectivity by spectrophotometer}

The spectrophotometer system is an emitting-receiving optical fiber system, which includes (1) visible spectrophotometer, (2) infrared spectrophotometer, (3) light source, (4) glass fiber, (5) RR sample stage with angle adjustment and angle scale, and (6) computer for processing data.

For the determination of angular retroreflectivity of RR materials using the emitting-receiving optical fiber system, the angular retroreflectivity with incident angle of $7^{\circ}$ of the prism RR sample was 0.41 , and this was used as the base retroreflectivity. Therefore, the angular retroreflectivity of the other RR materials can be determined through the reflection intensity relative to that of the prism RR sample and the spectral distribution of solar radiation. The function for determining angular retroreflectivity of sample is shown as:

$$
\rho_{\text {ret-ang }}=\rho_{\text {ret-base }} \cdot \int S(\gamma) \cdot E(\gamma) d \gamma / \int S_{\text {base }}(\gamma) \cdot E(\gamma) d \gamma
$$

where $\rho_{\text {ret-ang }}$ is the angular retroreflectivity of RR materials $[-] ; \rho_{\text {ret-base }}$ the retroreflectivity with incident angle of $7^{\circ}$ of the base prism RR sample [-]; $S(\gamma)$ the reflection intensity of these RR materials at different incident angles $[-] ; S_{\text {base }}(\gamma)$ the reflection intensity of the base prism RR sample at incident angle of $7^{\circ}[-]$; and $E(\gamma)$ the spectral distribution of hemispherical solar irradiance specified in ISO 9845-1 of International Organization for Standardization [12].

\subsection{Determination of retroreflectivity by thermal balance principle}

According to previous research [11], the retroreflectance of RR materials can be derived by subtracting the diffuse solar reflectivity measured with spectrophotometer (incident angle of light source is designed at $7^{\circ}$ ) from the total solar reflectivity evaluated by the thermal balance principle from temperatures measured outdoors (as shown in Figure 7) and is given by: 


$$
\rho_{\text {ret }}=\rho_{\text {tmp }}-\rho_{s p c}
$$

where $\rho_{\text {ret }}$ is the retroreflectivity of RR materials [-]; $\rho_{t m p}$ the solar reflectivity evaluated by the thermal balance in the outdoor environment $[-]$; and $\rho_{s p c}$ the solar reflectivity measured by spectrophotometer in the laboratory [-].

$\rho_{\text {tmp }}$ can be derived as:

$$
\rho_{\text {tmp }}=1-q_{r} / E_{i}
$$

where $q_{r}$ is the amount of shortwave irradiance $\left[\mathrm{W} / \mathrm{m}^{2}\right]$ and $E_{i}$ is the global irradiance on the inclined reflecting plate $\left[\mathrm{W} / \mathrm{m}^{2}\right]$.

$$
\begin{gathered}
q_{r}=q_{s}+q_{c v}+q_{c d} \\
q_{s}=-F_{s a} \varepsilon_{s} \varepsilon_{a} \sigma\left(T_{a}\right)^{4}-F_{s w} \varepsilon_{s} \varepsilon_{w} \sigma\left(T_{g}\right)^{4}+\varepsilon_{s} \delta\left(T_{1}\right)^{4} \\
q_{c v}=h\left(T_{1}-T_{a}\right) \\
q_{c d}=\mu / L\left(T_{1}-T_{2}\right)
\end{gathered}
$$

In the previous equations, $q_{s}$ is the amount of long-wave emittance $\left[\mathrm{W} / \mathrm{m}^{2}\right] ; q_{c v}$ the amount of convective heat transfer $\left[\mathrm{W} / \mathrm{m}^{2}\right], q_{c d}$ the amount of heat conduction to the insulation $\left[\mathrm{W} / \mathrm{m}^{2}\right]$; $F_{s a}$ the form factor from reflecting plate to air $[-] ; F_{s w}$ the form factor from reflecting plate to ground $[-]\left(=1-\mathrm{F}_{\mathrm{sa}}\right) ; \varepsilon_{s}$ the emissivity of the reflecting plate surface $[-] ; \varepsilon_{a}$ the atmospheric emissivity [-]); $\varepsilon_{w}$ the emissivity of the ground surface $[-] ; \delta$ the Stefan-Boltzmann constant $\left(=5.67 \times 10^{-8} \mathrm{~W} / \mathrm{m}^{2} \mathrm{~K}^{4}\right) ; h$ the convective heat transfer coefficient of a flat plate exposed to a stream of air $\left[\mathrm{W} / \mathrm{m}^{2} \mathrm{~K}\right] ; T_{1}$ the inner surface temperature of steel mounting plate $\left[{ }^{\circ} \mathrm{C}\right] ; T_{a}$ the air temperature $\left[{ }^{\circ} \mathrm{C}\right] ; T_{2}$ the outer surface temperature of steel mounting plate $\left[{ }^{\circ} \mathrm{C}\right] ; T_{g}$ the surface temperature of ground $\left[{ }^{\circ} \mathrm{C}\right] ; \mu$ the heat conductivity of the insulation $[\mathrm{W} / \mathrm{mK}]$; and $L$ is the thickness of the insulation [m].

The incident irradiance on the reflecting plate can be calculated by the Perez model [13]. The functions for determination of incident irradiance are as follows:

$$
\begin{gathered}
E_{i}=I_{s}+I_{d}+I_{r} \\
I_{s}=E_{e s} \times \cos i \\
I_{d}=E_{e d} \times(1+\cos \theta) / 2 \\
I_{r}=\rho_{g} \times E_{e g}(1-\cos \theta) / 2
\end{gathered}
$$

where $I_{s}$ is the direct irradiance on the inclined reflecting plate $\left[\mathrm{W} / \mathrm{m}^{2}\right] ; I_{d}$ the diffuse irradiance on the inclined reflecting plate $\left[\mathrm{W} / \mathrm{m}^{2}\right] ; I_{r}$ the irradiance reflected by ground to the inclined reflecting plate $\left[\mathrm{W} / \mathrm{m}^{2}\right] ; i$ the incident angle of solar irradiance on the inclined reflecting plate $[\mathrm{deg}] ; \theta$ the inclination angle of the reflecting plate [deg]; $\rho_{g}$ the albedo of the ground $[-] ; E_{e s}$, the direct irradiance $\left[\mathrm{W} / \mathrm{m}^{2}\right] ; E_{e d}$ the diffuse irradiance $\left[\mathrm{W} / \mathrm{m}^{2}\right]$; and $E_{e g}$ is the global irradiance $\left[\mathrm{W} / \mathrm{m}^{2}\right]$. 


\section{Development of glass bead RR materials}

Eight types of RR samples coated with glass beads with a refractive index of 1.5 or 1.9, added in amounts of 0.15 or $0.30 \mathrm{~kg} / \mathrm{m}^{2}$, on top of a reflective surface of white or silver paint (detailed in Table 1), were produced. All glass bead RR samples were $120 \mathrm{~mm}$ square plates. Additionally,

\begin{tabular}{lllll}
\hline Samples & $\begin{array}{l}\text { Reflective layer } \\
\text { color }\end{array}$ & $\begin{array}{l}\text { Refractive index of glass } \\
\text { bead }(\boldsymbol{n})\end{array}$ & $\begin{array}{l}\text { Diameter of glass bead } \\
(\mu \mathrm{m})\end{array}$ & $\begin{array}{l}\text { Density of glass beads } \\
\left(\mathbf{k g} / \mathbf{m}^{2}\right)\end{array}$ \\
\hline S1 & White & 1.5 & $106-850$ & 0.30 \\
S2 & White & 1.5 & $106-850$ & 0.15 \\
S3 & White & 1.9 & $106-850$ & 0.30 \\
S4 & White & 1.9 & $106-850$ & 0.15 \\
S5 & Silver & 1.5 & $106-850$ & 0.30 \\
S6 & Silver & 1.5 & $106-850$ & 0.15 \\
S7 & Silver & 1.9 & $106-850$ & 0.30 \\
S8 & Silver & 1.9 & $106-850$ & 0.15 \\
\hline
\end{tabular}

Table 1. Detailed characteristics of developed glass bead RR samples.

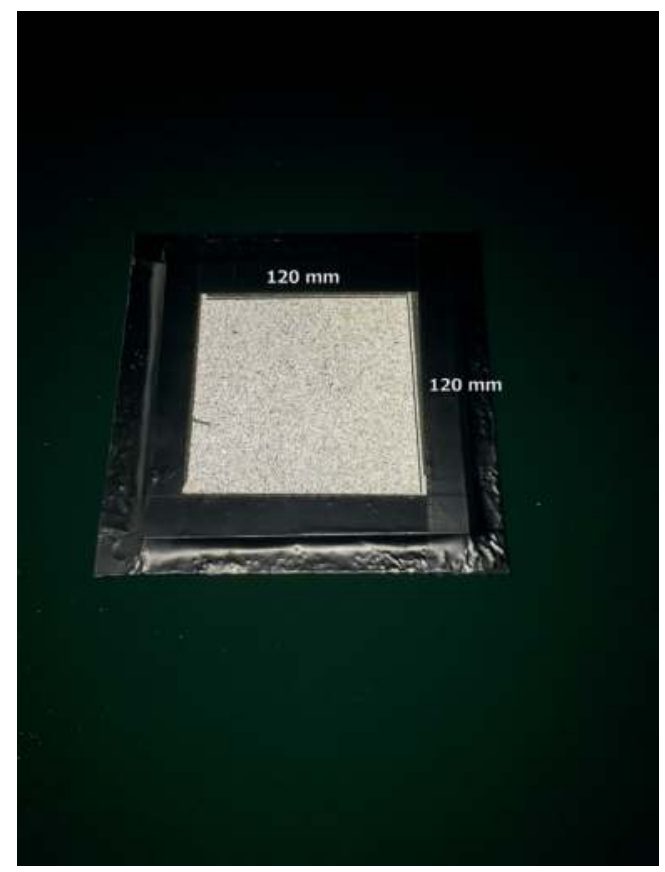

Figure 8. Appearance of developed glass bead RR materials. 
because the glass covering could improve the durability of RR material as found in previous research [8], the surface of all glass bead RR samples was designed with a glass sheet covering with high transmittance (visible transmittance $91.3 \%$, UV transmittance $92.5 \%$ ), a reflectivity of $2 \%$, and high strength. The appearance and structure of the developed glass bead RR sample are shown in Figures 8 and 9.

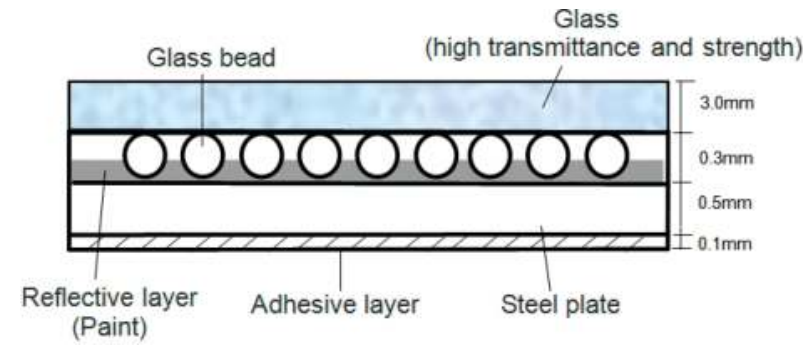

Figure 9. Structure view of developed glass bead RR materials.

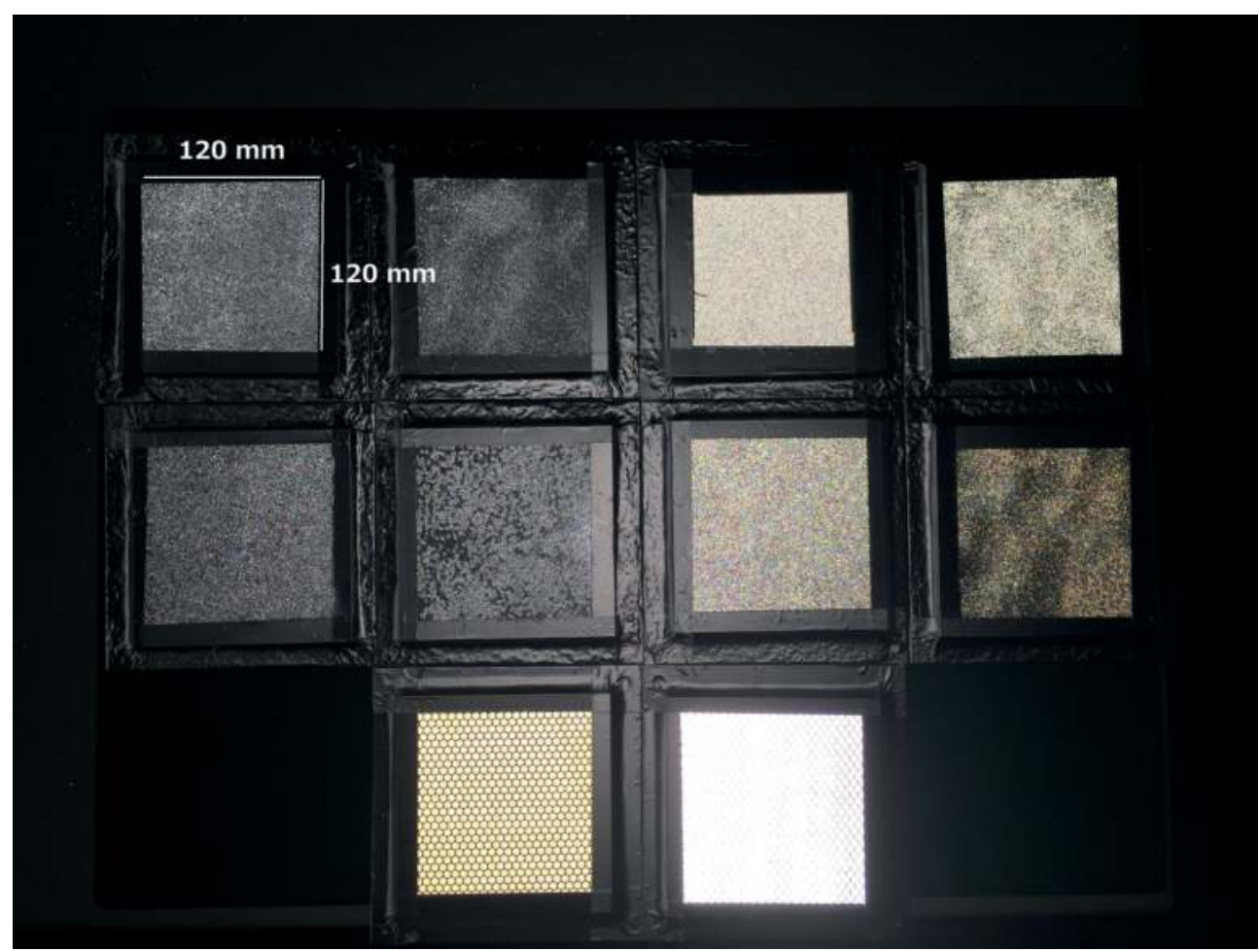

Figure 10. Retroreflection effect of developed glass bead RR materials when the artificial light source is incident on their surface. 
In addition, for comparison, two types of commercial RR sheet (capsule and prism) samples (KICTEC Corporation) were also produced. The retroreflection effect of all RR samples when the artificial light source is incident on the surface is shown in Figure $\mathbf{1 0 .}$

It is shown that except for the two types of commercial RR sheets, retroreflection intensity of the developed glass bead RR samples with a refractive index of 1.9 and a white reflective layer is much stronger than that with a reflective index of 1.5 and a silver reflective layer.

\section{Optical analysis of glass bead RR materials}

The reflection intensity of 10 types of RR samples at different incident angles was measured by a specific spectrophotometer system over different incident angles from $-85^{\circ}$ to $85^{\circ}$ with steps
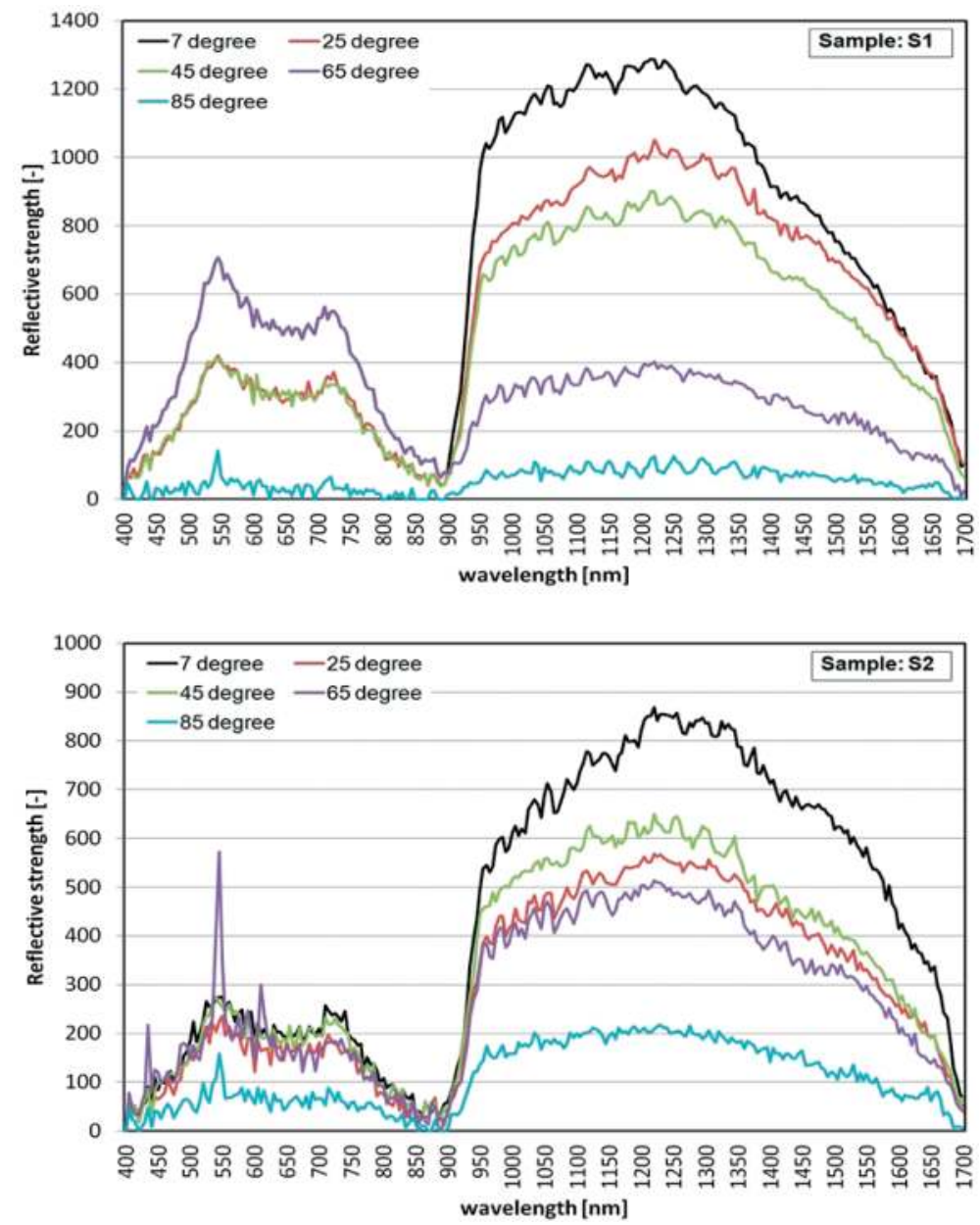

Figure 11. Reflection intensity of RR samples (S1 and S2). 
of about $20^{\circ}$. The results are shown in Figures 11-15, where the y-axis scale is a raw data output of signal strength for each wavelength with a maximum reading of about 60,000 . The graphed values are data from $+7^{\circ}$ to $+85^{\circ}$. The measured values from $-7^{\circ}$ to $-85^{\circ}$ were not significantly different.

In addition, the angular retroreflectivity of 10 types of RR samples is calculated by using Eq. (1) and shown in Table 2.

For the sake of analyzing the angular distribution of reflection intensity of these developed RR materials, the samples (S1, S3, S5, S7, S9: capsule sheet and S10: prism sheet) are chosen and
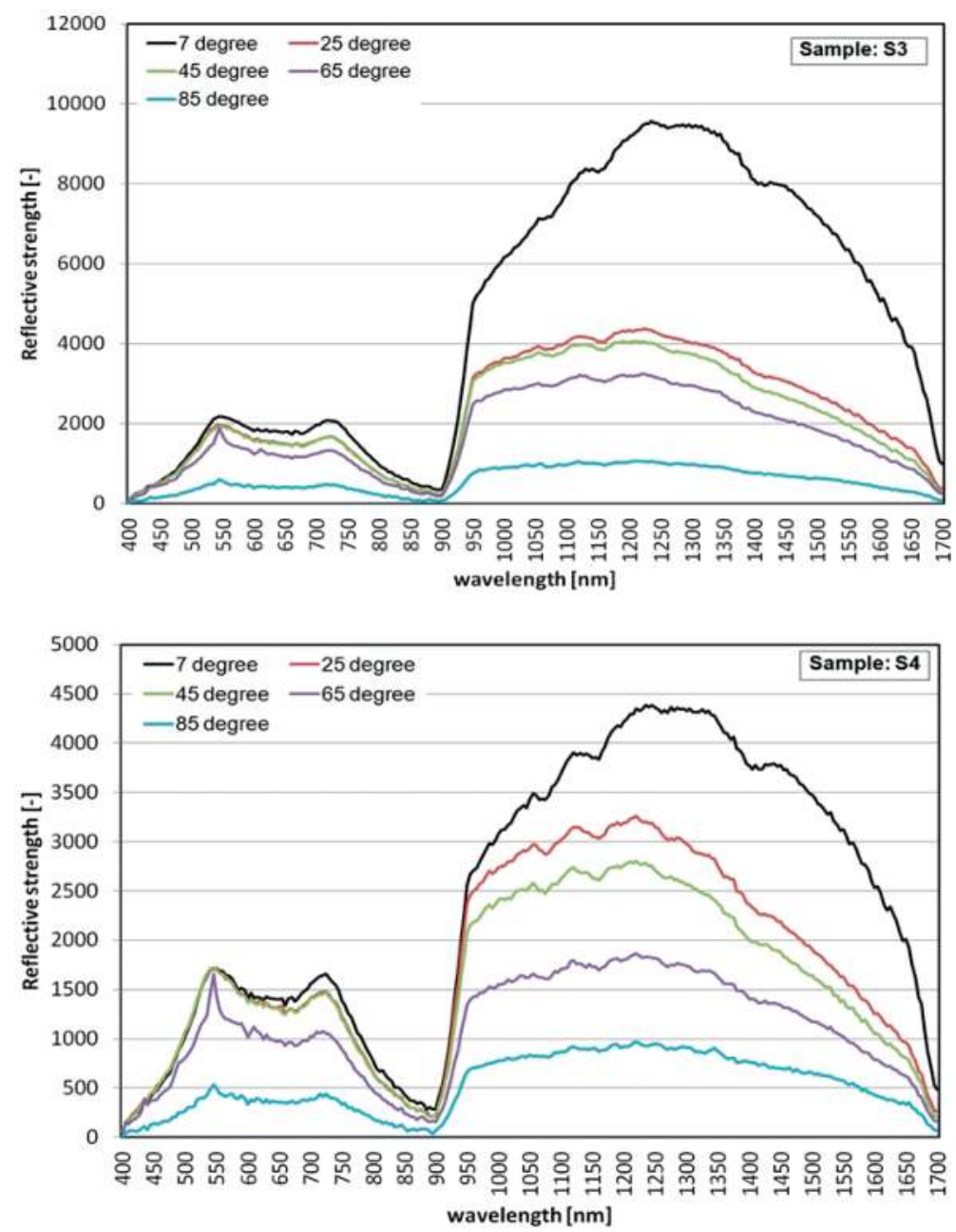

Figure 12. Reflection intensity of RR samples (S3 and S4). 

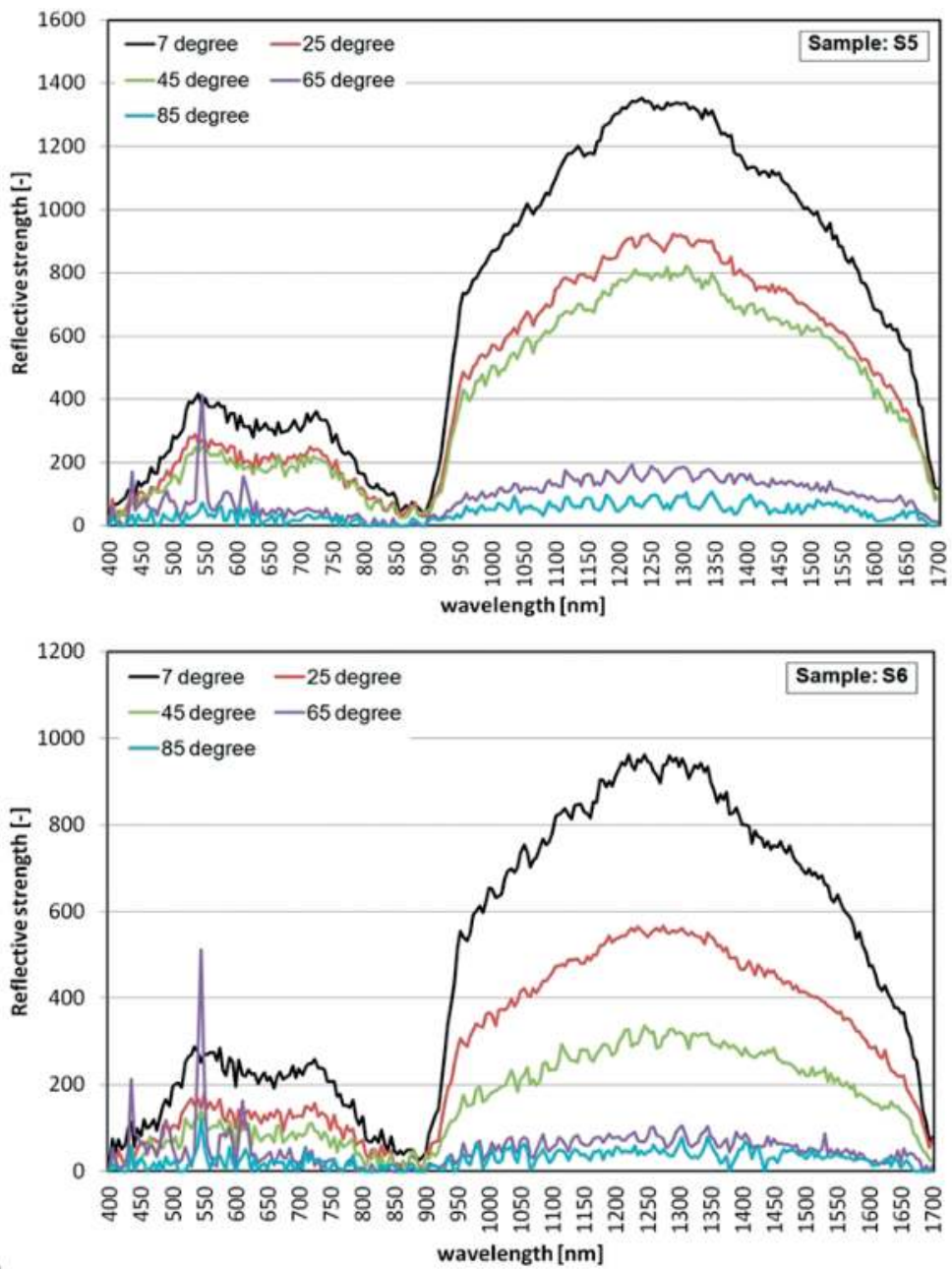

Figure 13. Reflection intensity of RR samples (S5 and S6).

characterized in terms of angular distribution of the reflection intensity $\left(-80^{\circ} \sim 80^{\circ}\right)$ by varying the incident angle of these RR samples from $10^{\circ}$ to $80^{\circ}$ with steps of about $20^{\circ}\left(10^{\circ}, 30^{\circ}, 60^{\circ}\right.$, and $\left.80^{\circ}\right)$. The detailed angular distribution of reflection intensity of chosen RR samples (S1, S3, S5, S7, S9: capsule sheet and S10: prism sheet) is shown in Table 3. Reflection to negative incident angle is the "specular reflection".

It is shown that except for the commercial capsule and prism RR samples, the developed glass bead RR materials with a refractive index of 1.9 are more efficient than those with a 

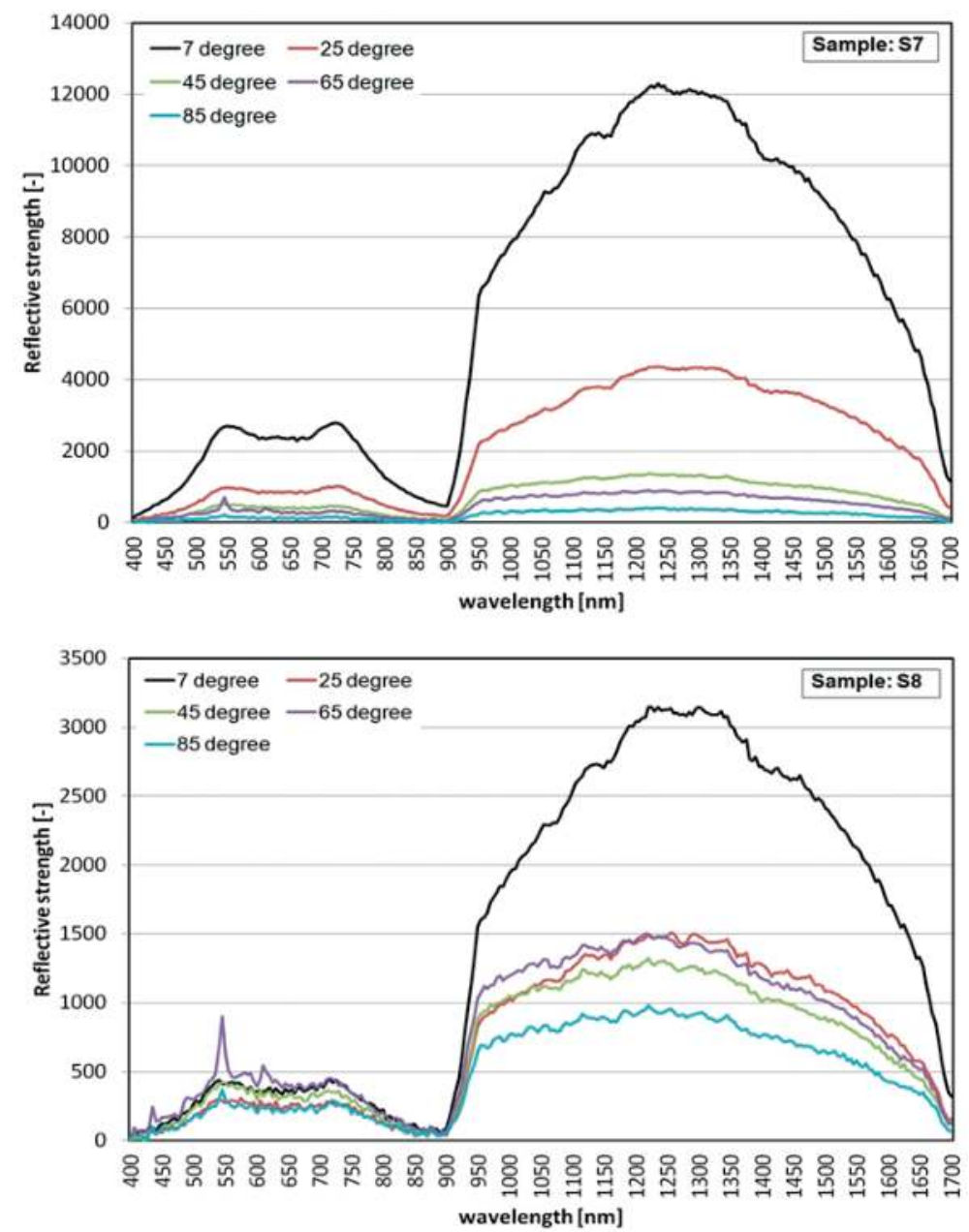

Figure 14. Reflection intensity of RR samples (S7 and S8).

refractive index of 1.5 for application to building coatings at low incident angles of sunlight.

Compared to commercial capsule and prism RR materials, the glass bead RR samples produced in this study are relatively weaker in RR directional characteristics. However, the cost of these developed glass bead RR materials is relatively lower than commercial capsule and prism RR materials. Therefore, as long as the durability of these developed glass bead RR materials can be ensured, it is desirable to develop such low-cost glass bead RR materials and possibly apply to exterior wall surface of buildings. 


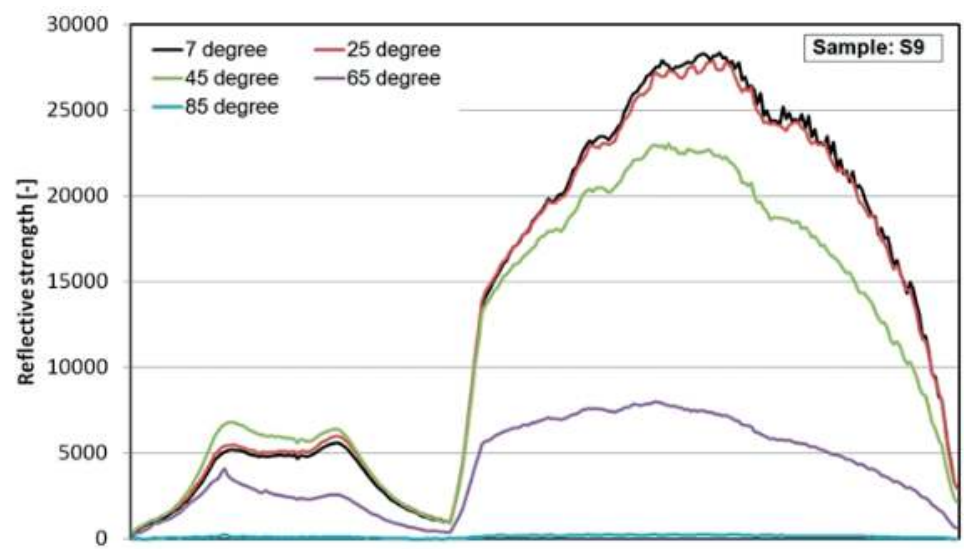

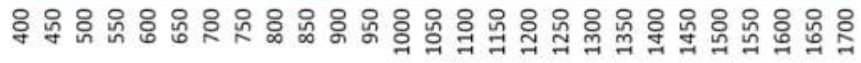
wavelength [nm]

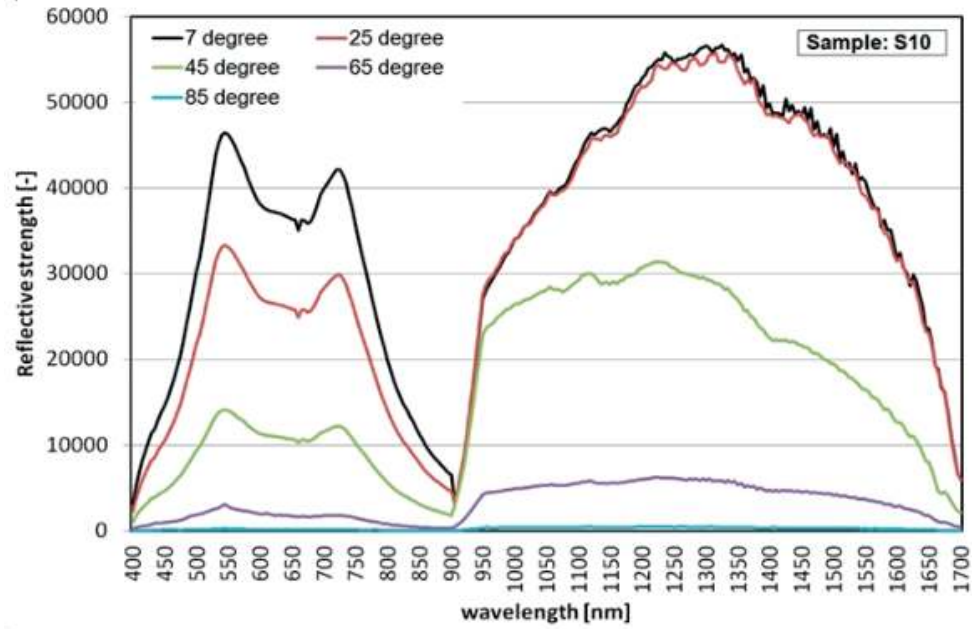

Figure 15. Reflection intensity of RR samples (S9 and S10).

\begin{tabular}{lllllllllll}
\hline Angle & \multicolumn{10}{c}{ Sample } \\
\cline { 2 - 10 } & S1 & S2 & S3 & S4 & S5 & S6 & S7 & S8 & S9 (capsule) & S10 (prism) \\
\hline$-90^{\circ}$ & 0.0 & 0.0 & 0.0 & 0.0 & 0.0 & 0.0 & 0.0 & 0.0 & 0.0 & 0.0 \\
$-85^{\circ}$ & 0.1 & 0.1 & 0.8 & 0.7 & 0.1 & 0.0 & 0.3 & 0.6 & 0.2 & 0.2 \\
$-65^{\circ}$ & 0.4 & 0.4 & 2.3 & 1.4 & 0.1 & 0.1 & 0.6 & 1.0 & 5.5 & 3.1 \\
$-45^{\circ}$ & 0.9 & 0.4 & 2.8 & 2.1 & 0.5 & 0.2 & 0.9 & 0.9 & 15.2 & 15.7 \\
$-25^{\circ}$ & 0.6 & 0.4 & 3.1 & 2.3 & 0.6 & 0.4 & 2.8 & 1.0 & 17.9 & 36.9
\end{tabular}




\begin{tabular}{lllllllllll}
\hline Angle & \multicolumn{10}{c}{ Sample } \\
\cline { 2 - 10 } & S1 & S2 & S3 & S4 & S5 & S6 & S7 & S8 & S9 (capsule) & S10 (prism) \\
\hline$-7^{\circ}$ & 0.7 & 0.6 & 6.2 & 3.2 & 0.9 & 0.6 & 7.9 & 1.9 & 18.0 & 41.1 \\
$7^{\circ}$ & 0.7 & 0.6 & 6.2 & 3.2 & 0.9 & 0.6 & 7.9 & 1.9 & 18.0 & 41.1 \\
$25^{\circ}$ & 0.6 & 0.4 & 3.1 & 2.3 & 0.6 & 0.4 & 2.8 & 1.0 & 17.9 & 36.9 \\
$45^{\circ}$ & 0.9 & 0.4 & 2.8 & 2.1 & 0.5 & 0.2 & 0.9 & 0.9 & 15.2 & 15.7 \\
$65^{\circ}$ & 0.4 & 0.4 & 2.3 & 1.4 & 0.1 & 0.1 & 0.6 & 1.0 & 5.5 & 3.1 \\
$85^{\circ}$ & 0.1 & 0.1 & 0.8 & 0.7 & 0.1 & 0.0 & 0.3 & 0.6 & 0.2 & 0.2 \\
$90^{\circ}$ & 0.0 & 0.0 & 0.0 & 0.0 & 0.0 & 0.0 & 0.0 & 0.0 & 0.0 & 0.0
\end{tabular}

Table 2. Angular retroreflectivity of 10 types of RR samples with different incident angles, $\times 10^{-2}[-]$.

\begin{tabular}{|c|c|c|c|c|c|c|c|c|c|}
\hline Incidence $\left(^{\circ}\right)$ & 10 & 30 & 60 & 80 & Incidence $\left(^{\circ}\right)$ & 10 & 30 & 60 & 80 \\
\hline S1 & & & & & S3 & & & & \\
\hline $10^{\circ}$ & 5.1 & 3.4 & 2.3 & 2.0 & $10^{\circ}$ & 15.8 & 3.3 & 2.4 & 2.2 \\
\hline $30^{\circ}$ & 3.3 & 5.0 & 2.4 & 2.0 & $30^{\circ}$ & 4.3 & 12.0 & 2.5 & 2.2 \\
\hline $60^{\circ}$ & 2.6 & 2.3 & 4.6 & 2.1 & $60^{\circ}$ & 2.8 & 2.9 & 11.0 & 2.9 \\
\hline $80^{\circ}$ & 2.0 & 2.0 & 2.1 & 2.5 & $80^{\circ}$ & 2.1 & 2.1 & 2.2 & 3.5 \\
\hline $0^{\circ}$ & 4.0 & 2.5 & 2.4 & 2.0 & $0^{\circ}$ & 4.8 & 2.9 & 2.7 & 2.2 \\
\hline$-80^{\circ}$ & 2.2 & 2.0 & 2.3 & 12.2 & $-80^{\circ}$ & 2.0 & 2.2 & 2.5 & 12.3 \\
\hline$-60^{\circ}$ & 2.4 & 2.1 & 8.3 & 3.1 & $-60^{\circ}$ & 2.8 & 2.6 & 9.0 & 3.9 \\
\hline$-30^{\circ}$ & 2.7 & 8.8 & 2.6 & 2.0 & $-30^{\circ}$ & 3.7 & 8.0 & 2.2 & 2.0 \\
\hline$-10^{\circ}$ & 7.7 & 2.5 & 2.5 & 2.0 & $-10^{\circ}$ & 7.8 & 2.8 & 2.6 & 2.2 \\
\hline S5 & & & & & S7 & & & & \\
\hline $10^{\circ}$ & 5.8 & 2.3 & 2.0 & 1.9 & $10^{\circ}$ & 16.0 & 2.6 & 2.3 & 2.0 \\
\hline $30^{\circ}$ & 2.4 & 3.6 & 2.1 & 1.9 & $30^{\circ}$ & 3.4 & 12.7 & 2.6 & 2.1 \\
\hline $60^{\circ}$ & 2.1 & 2.1 & 3.2 & 1.9 & $60^{\circ}$ & 2.4 & 2.1 & 5.2 & 2.2 \\
\hline $80^{\circ}$ & 2.0 & 2.0 & 2.0 & 2.6 & $80^{\circ}$ & 2.1 & 2.0 & 2.0 & 3.8 \\
\hline $0^{\circ}$ & 4.3 & 2.3 & 2.1 & 1.9 & $0^{\circ}$ & 5.7 & 2.3 & 1.2 & 1.1 \\
\hline$-80^{\circ}$ & 2.0 & 2.0 & 2.0 & 8.7 & $-80^{\circ}$ & 2.2 & 2.0 & 2.2 & 9.1 \\
\hline$-60^{\circ}$ & 2.1 & 2.1 & 7.0 & 2.4 & $-60^{\circ}$ & 2.4 & 2.1 & 9.7 & 3.2 \\
\hline$-30^{\circ}$ & 2.3 & 5.7 & 2.2 & 1.9 & $-30^{\circ}$ & 3.7 & 9.0 & 2.5 & 2.3 \\
\hline$-10^{\circ}$ & 5.7 & 2.7 & 2.1 & 1.9 & $-10^{\circ}$ & 8.4 & 2.3 & 2.3 & 2.0 \\
\hline S9 (capsule sheet) & & & & & S10 (prism sheet) & & & & \\
\hline $10^{\circ}$ & 35.0 & 4.4 & 2.3 & 2.0 & $10^{\circ}$ & 45.0 & 4.6 & 3.3 & 4.3 \\
\hline $30^{\circ}$ & 3.2 & 32.1 & 2.3 & 2.1 & $30^{\circ}$ & 4.2 & 40.0 & 3.4 & 5.4 \\
\hline
\end{tabular}




\begin{tabular}{llllllllll}
\hline Incidence $\left(^{\circ}\right)$ & $\mathbf{1 0}$ & $\mathbf{3 0}$ & $\mathbf{6 0}$ & $\mathbf{8 0}$ & Incidence $\mathbf{(}^{\circ}$ ) & $\mathbf{1 0}$ & $\mathbf{3 0}$ & $\mathbf{6 0}$ & $\mathbf{8 0}$ \\
\hline $60^{\circ}$ & 2.4 & 2.5 & 12.3 & 2.4 & $60^{\circ}$ & 3.8 & 4.2 & 7.0 & 4.0 \\
$80^{\circ}$ & 2.0 & 2.0 & 2.2 & 4.5 & $80^{\circ}$ & 2.9 & 3.1 & 2.2 & 3.1 \\
$0^{\circ}$ & 13.0 & 3.8 & 1.8 & 1.2 & $0^{\circ}$ & 7.8 & 4.7 & 1.9 & 1.2 \\
$-80^{\circ}$ & 2.2 & 2.1 & 2.6 & 26.7 & $-80^{\circ}$ & 2.5 & 2.6 & 4.5 & 24.0 \\
$-60^{\circ}$ & 2.4 & 2.4 & 28.0 & 7.0 & $-60^{\circ}$ & 2.6 & 3.3 & 21.0 & 3.2 \\
$-30^{\circ}$ & 4.5 & 25.4 & 3.3 & 2.1 & $-30^{\circ}$ & 3.6 & 15.4 & 3.5 & 3.6 \\
$-10^{\circ}$ & 23.4 & 5.0 & 2.3 & 2.0 & $-10^{\circ}$ & 10.6 & 4.1 & 3.0 & 3.6 \\
\hline
\end{tabular}

Table 3. Angular distribution of reflection intensity of chosen RR samples, $\times 10^{3}[-]$.

\section{Verification on durability of glass bead RR materials}

For possible application of these glass bead RR materials to building facades, the durability of these developed glass bead RR samples should be verified. Therefore, the change in solar reflectivity of these developed glass bead RR samples was evaluated by exposed experiments in the outdoor environment. The experimental stand is shown in Figure 16. As an example, the change in solar reflectivity (for incident angle of solar radiation: $5^{\circ}$ ) of four chosen glass bead RR samples (S1, S3, S5, and S7) for approximately 1 year (about 368 days) exposure to outdoor environments is shown in Figure 17.

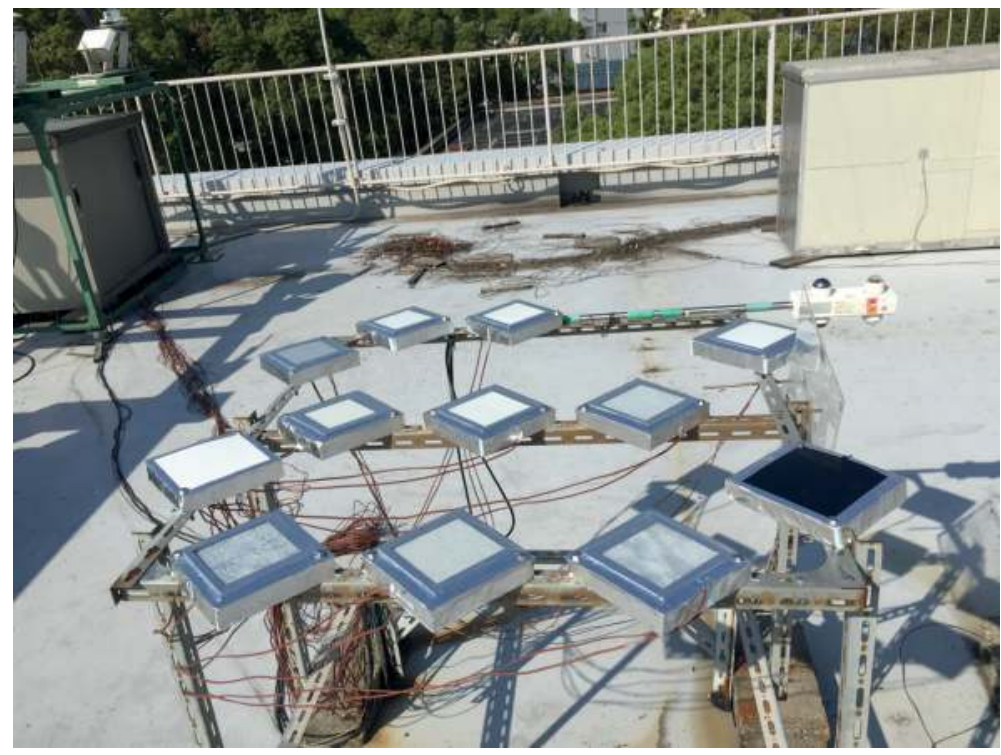

Figure 16. Experimental stand for deriving retroreflectivity of developed glass bead RR samples. 


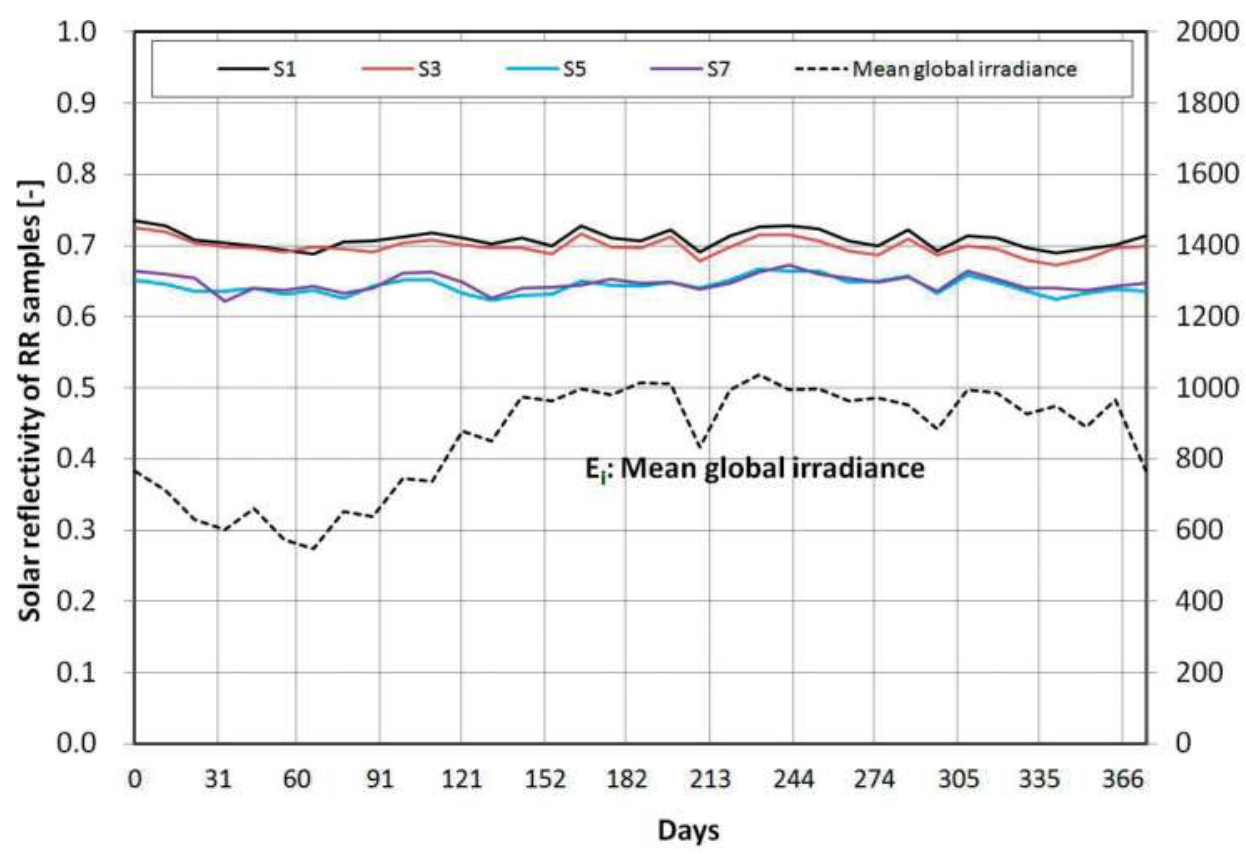

Figure 17. Change in solar reflectivity at incident angle of solar radiation of $5^{\circ}$ for four chosen glass bead RR samples (S1, S3, S5, and S7).

The results show that the solar reflectivity of the developed four chosen glass bead RR samples has a limited decrease of only about 0.02 for long-term exposure (about 368 days) in the outdoor environment.

It is considered that the durability of four chosen glass bead RR materials can be ensured during the 368-day exposure in the outdoor environment. In addition, it is also shown that the solar reflectivity of glass bead RR samples (S1 and S3) with white reflective layers is about 0.07 higher than that with silver reflective layers (S5 and S7).

Whether these developed glass bead RR materials meet the durability requirements of building exterior wall surface materials will take longer time to be validated.

\section{Influence of glass bead RR façade on pedestrians and proposal of suppression method}

According to the research by Takebayashi [14], the effectiveness of applying RR materials to building façades was evaluated in regard to avoiding adverse effects on pedestrians. As shown in Figure 18, the result is indicated that the RR materials can be considered for use on building façades below the third floor in order to avoid impacts on pedestrians from the reflection of solar radiation. 


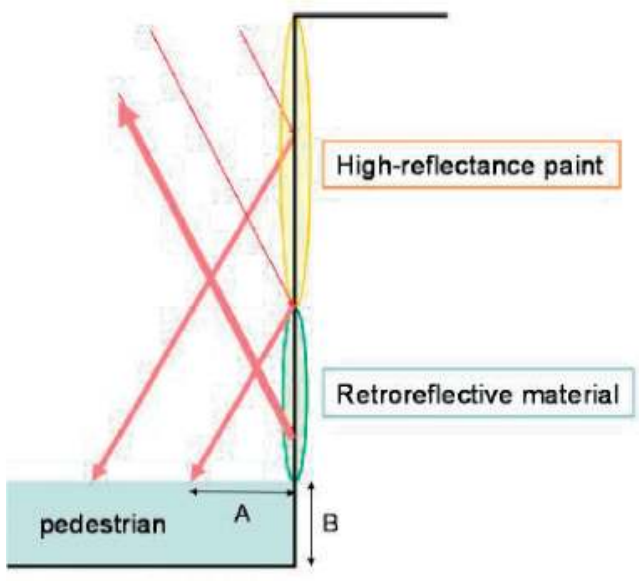

Figure 18. Effect of RR façade on pedestrian [14].

For the glass bead RR material, if it was applied to a building façade, when the solar altitude angle is large such as $60^{\circ}$, the specular reflection component accounts for a relatively large proportion of the whole reflection (as shown in Figure 19). Thus, it is essential to suppress the specular reflection which is emitted from a glass bead RR façade by using an appropriate technical method that is described and shown in Figure 20.

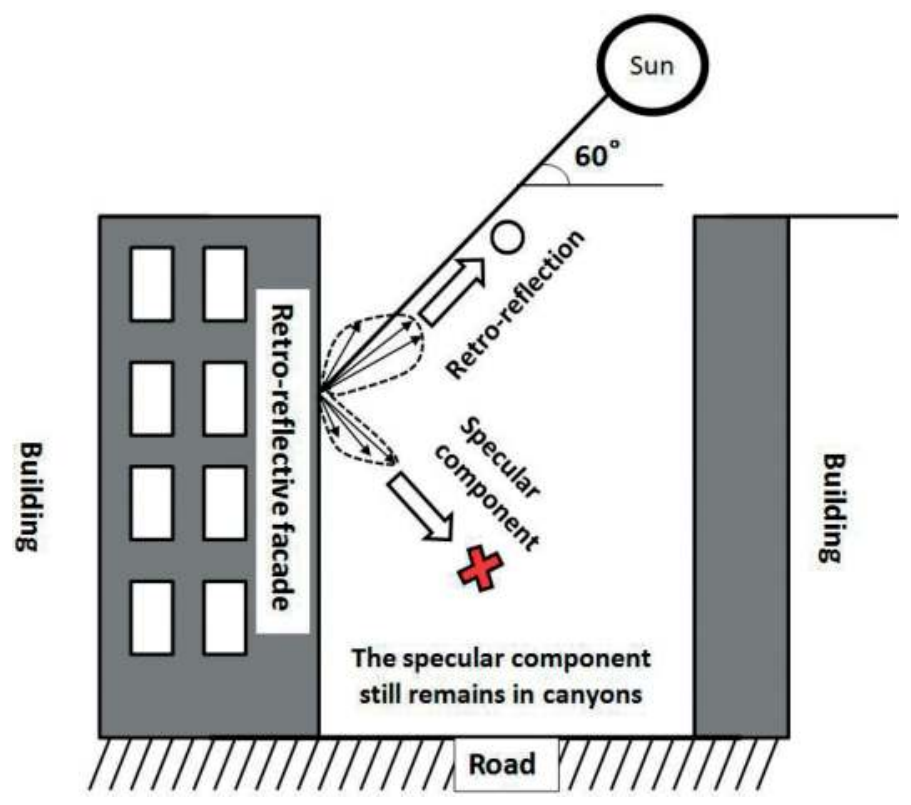

Figure 19. A $2 \mathrm{D}$ simulation of the specular reflection component from a glass bead RR façade. 

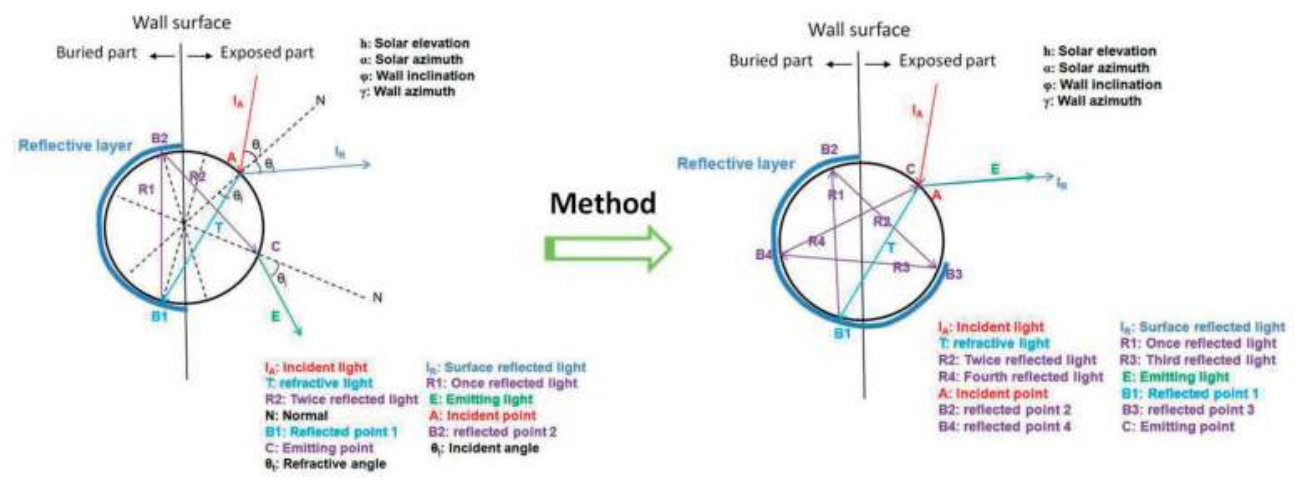

Figure 20. Proposal of avoiding the specular reflection component emitted from a glass bead RR facade.

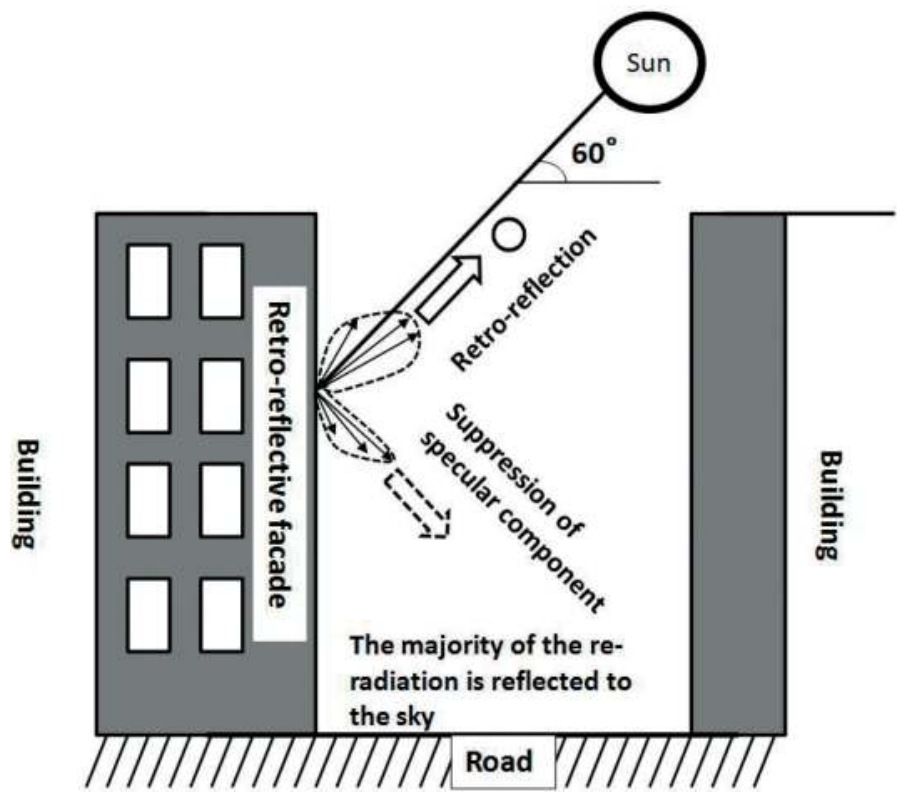

Figure 21. A 2D simulation after the adoption of a proposal to avoid specular reflection effect.

The effect of a newly designed glass bead RR facade on pedestrians and thermal radiation of urban environment could be improved after adopting the method of suppressing the specular reflection emitted from the RR façade of buildings (as shown in Figure 21).

\section{Summary and conclusions}

This chapter shows the application of glass bead materials in building exterior wall surfaces. Two main methods for deriving retroreflectivity of glass bead RR materials were analyzed. 
Several types of glass bead RR building coating samples were developed. For possible application of these samples to building coatings and verification of their long-term durability, the optical and durable experiments of these samples were carried out. The theoretical and technical method to prevent the specular reflection which is emitted from glass bead RR façade is proposed in this study.

We can summarize the knowledge as follows:

1. Methods to derive the retroreflectivity of RR materials are proposed and described in this study. One is measured by a spectrophotometer system and the other is determined by a thermal balance principle of surface.

2. Production of glass bead RR samples with low cost that is possibly applied to building coatings is carried out in this study.

3. The reflection directional characteristics of developed glass bead samples were measured by using an emitting-receiving optical fiber system. It is shown that except for commercial capsule and prism RR samples, the developed glass bead RR materials with a refractive index of 1.9 are more efficient than those with a refractive index of 1.5 for application to building coatings as RR materials at low incident angles of sunlight.

4. The long-term durability of the developed glass bead RR samples was verified through exposure experiment in the outdoor environment. It is shown that the durability of the developed glass bead RR materials can be ensured during the 368-day exposure in the outdoor environment, and more time is needed to continue this durability experiment.

5. A proposal of theoretical and technical methods to prevent the specular reflection from the glass bead RR façade is briefly described in this study.

\section{Author details}

Jihui Yuan

Address all correspondence to: yuanjihui@hotmail.co.jp

Department of Housing and Environmental Design, Graduate School of Human Life Science, Osaka City University, Osaka, Japan

\section{References}

[1] Nishioka M, Inoue S, Sakai K. Retroreflective properties calculating method based on geometrical-Optics analysis performance evaluation of solar retroreflectors. Journal of Environmental Engineering. 2008;73(633):1249-1254. DOI: 10.3130/aije.73.1249 
[2] Rossi F, Pisello AL, Nicolini A, Filipponi M, Palombo M. Analysis of retro-reflective surfaces for urban heat island mitigation: A new analytical model. Applied Energy. 2014;114: 621-631. DOI: 10.1016/j.apenergy.2013.10.038

[3] Han Y, Taylor JE, Pisello AL. Toward mitigating urban heat island effects: Investigating the thermal-energy impact of bio-inspired retro-reflective building envelopes in dense urban settings. Energy and Buildings. 2015;102:380-389. DOI: 10.1016/j.enbuild.2015.05.040

[4] Yuan J, Emura K, Farnham C. Geometrical-optics analysis of reflective glass beads applied to building coatings. Solar Energy. 2015;122:997-1010. DOI: 10.1016/j.solener.2015.10.015

[5] Yao Sangyo Co., Ltd. 3M ${ }^{\mathrm{TM}}$ Enclosed Lens Type Reflective Sheet 1500 Series. Available at: http://www.yao-sangyo.co.jp/sign/envelop_1500.html

[6] Yao Sangyo Co., Ltd. 3M ${ }^{\mathrm{TM}}$ Capsule Prism Type High Brightness Reflection Sheet PX 8400 Series. Available at: http://www.yao-sangyo.co.jp/sign/prism_px8400.html

[7] Yuan J, Emura K, Farnham C, Sakai H. Application of glass beads as retro-reflective facades for urban heat island mitigation: Experimental investigation and simulation analysis. Building and Environment. 2016;105:140-152. DOI: 10.1016/j.buildenv.2016.05.039

[8] Yuan J, Farnham C, Emura K. Development of a retro-reflective material as building coating and evaluation on albedo of urban canyons and building heat loads. Energy and Buildings. 2015;103:107-117. DOI: 10.1016/j.enbuild.2015.06.055

[9] Tao F, Yao J. Influence of retro-reflective material on public buildings energy consumption in different climate regions. Journal of Chemical and Pharmaceutical Research. 2013; 5(9):447-452. Available at: http://www.jocpr.com

[10] Yuan J, Emura K, Sakai H, Farnham C, Lu S. Optical analysis of glass bead retro-reflective materials for urban heat island mitigation. Solar Energy. 2016;132:203-213. DOI: 10.1016/j. solener.2016.03.011

[11] Yuan J, Farnham C, Emura K. A study on the accuracy of determining the retro-reflectance of retro-reflective material by heat balance. Solar Energy. 2015;122:419-428. DOI: 10.1016/j. solener.2015.08.040

[12] ISO 9050: Glass in building - Determination of light transmittance, solar direct transmittance, total solar energy transmittance, ultraviolet transmittance and related glazing factors (2003). Available at: http://www.webstore.jsa.or.jp

[13] Perez RR, Ineichen P, Seals R, Michalsky J, Stewart R. Modeling daylight availability and irradiance components from direct and global irradiance. Solar Energy. 1990;44(5):271-289. DOI: 10.1016/0038-092X(90)90055-H

[14] Takebayashi H. High-reflectance technology on building façades: Installation guidelines for pedestrian comfort. Sustainability. 2016;8(785):1-9. DOI: 10.3390/su8080785 
